\title{
Capsule Commentary on Kobayashi et al., Cognitive Function and Health Literacy Decline in a Cohort of Aging English Adults
}

\author{
Tresa McNeal, $M D^{1,2}$ \\ ${ }^{1}$ Texas A\&M HSC College of Medicine, Temple, TX, USA; ${ }^{2}$ Baylor Scott \& White Health, Temple, TX, USA.
}

J Gen Intern Med 30(7):1002

DOI: $10.1007 / \mathrm{s} 11606-015-3243-4$

(c) Society of General Internal Medicine 2015

A wareness of health literacy as a recognized factor affecting patients and their families has grown over the past 15 years, since Kirsch and colleagues first reported results of the 1992 National Adult Literacy Survey in 2002. ${ }^{1}$ This representative survey brought to light the literacy challenges faced on many levels within our country as we deal with people in our population who have limited academic achievement or ability to interpret complex language.

In 2007, Miller et al. described challenges experienced specifically by the elderly and found that $44 \%$ of patients aged 65 years and older in the 1992 NALS study had either inadequate or marginal health literacy. ${ }^{2}$ In addition, it is been shown that limited health literacy is associated with worse outcomes. ${ }^{3}$

In this issue, Kobayashi et al. provide a glimpse at cognitive function and health literacy decline over time in a cohort of English subjects from the ages of 52 years or older as part of the English Longitudinal Study of Ageing. ${ }^{4}$ This was done by using a reading comprehension assessment of a fictitious medicine label and assessing cognitive function decline between baseline (2004-2005) and follow-up assessment 6 years later (2010-2011). A total of close to 5,000 patients participated in the original and follow-up studies. Almost $20 \%$ of participants experienced a decline in health literacy; those over 80 experienced a $38 \%$ decline. Other risk factors for declining literacy included being male, non-white, and having low educational attainment and low occupational class. They found striking social inequities, with minorities and those from deprived backgrounds particularly vulnerable to literacy decline. While most of the decline in literacy could be explained by decline in cognitive function, the disparities in literacy decline among these vulnerable groups persisted despite adjustment for cognition.

This is useful information; physicians should be aware of the risk of declining literacy in their patients. Effective communication requires that providers be cognizant of deficits in health literacy and that tailored approaches are used to meet the informational needs of individual patients. As Kobayashi points out, research to determine if interventions can help maintain literacy skills is needed.

Conflict of Interest: The author declares that she does not have a conflict of interest.

Corresponding Author: Tresa McNeal, MD; Texas AM HSC College of Medicine, Bryan, TX 77807, USA (e-mail: tmcneal@sw.org).

\section{REFERENCES}

1. Kirsch I, Jungeblut K, Jenkins L, Kolstad A. Adult Literacy in America: A First Look at the Findings of the National Adult Literacy Survey. 3rd ed. (NCES 1993-275). Washington D.C. p. xv-xxiii.

2. Miller M, Degenholtz H, Gazmararian J, Lin C, Ricci E, Sereika S. Identifying elderly at greatest risk of inadequate health literacy; A predictive model for population-health decision makers. Res Soc Admin Pharm. 2007;3:70-85.

3. Nielson-Bohlman L, Panzer AM, Kindig DA, eds. Health Literacy: A Prescription to End Confusion. Washington, DC: National Academies Press; 2004.

4. Kobayahi L, Wardle J, Wolf $\mathbf{M}$, von Wagner C. Cognitive function and health literacy decline in a cohort of aging English adults. JGIM. doi:10.1007/ s11606-015-3206-9. 